\title{
Educational Content of Today The Understanding of Architecture as a Collective Art
}

GRO LAUVLAND

Norwegian University of Science and Technology 
Our understanding of the world is manifested in what we make and produce. Through the last 250 years there has been a change in the understanding of man's place in the world. Our way of building is characterized by market economy and controlled production processes - as if we can control everything through our consciousness. Both the given nature and what is transferred to us through history, are regarded as resources made for us. Today our understanding of the world makes the cities more and more similar. This understanding of nature and culture challenges our human conditions.

As human beings, we are embedded in the place, according to both Martin Heidegger and Maurice Merleau-Ponty. In line with their understanding the Norwegian architect and theorist Christian Norberg-Schulz argued, for instance in Stedskunst (1995), that it is the qualities of the place we identify with, and which makes it possible for us to feel at home.

Since Vitruvius, architectural quality has been connected to the unit of beauty, usability and durability. Architecture belongs to the arts; it unites aesthetics and ethics. This means that architecture offers a resistance towards the consumer society of today; architecture is neither the same as culture, nor as mere building. Have we lost the sight of the importance of the place - of the concrete, qualitative and sensational characteristics? What does this mean for the education of architects and for the architectural production?

As our understanding of the world is manifested in what we make and produce, I would like to mention three different ways of seeing the world and how these approaches are related both to architectural practise and to the education of architects. Both Heidegger and the political thinker Hannah Arendt argues that cognition and thought are not the same. Arendt writes that cognition '...the chief manifestation of the cognitive processes, by which we acquire and store up knowledge, is the sciences. (...) Cognition always pursues a definite aim, (...) but once this aim is reached, the cognitive process has come to an end.' And she continues: 'Thought, the source of art works, is manifest without transformation or transfiguration in all great philosophy (...) Thought (...) has neither an end nor an aim outside itself, and it does not even produce results... The activity of thinking is as relentless and repetitive as life itself...'

Norberg-Schulz acknowledge this difference between cognition and thought, and he also talks about, related to thought, a poetical way of understanding - an understanding that reaches out for what is given through nature and history. This presentation will thematise the importance of 'a poetical understanding' in the field of architecture. 
The early modernists wanted to re-establish architecture as an art form, however, they did not truly succeed. Many places were destroyed during the last Century due to the World War I and II, but also due to our lack of understanding. Within the academic society, the $20^{\text {th }}$ Century was characterized by a continuously discussion over this question - a discussion where Norberg-Schulz also participated: What is the academic foundation of the field of architecture?

Today the PhD-production in the architectural institutions, asks for a scientific cognition - a way of seeing that pursuits a definite aim. The architectural theory is losing sight of both architecture as an art form, and of the understanding of architectural quality. This has led to a deep split between architectural theory and practise. Diminishing the split asks for a thematising of our ways of seeing both nature and culture, like Shelly McNamarra and Yvonne Farrell did in the Venice biennale in 2018.

The understanding of architecture as an art form, implies an emphasis of our being-here; we are embedded in the place with our senses and feelings, as well as with our consciousness: 'Our own body is the world as the heart is in the organism', says Merleau-Ponty in The Phenomenology of Perception (1962). A scientific approach to architecture can only deal with parts of the academic field. Today the education of architects needs to make explicit the epistemological ground of the field of architecture, onto which the scientific approaches must be based.

A scientific and economical approach characterizes most of what is built today - not a poetical approach, and this means that we as architects also need to address the importance of a change of mindset within the culture and society. Architects have - here quoting the architect Daniel Rosbottom - 'responsibilities beyond themselves, to people, the urban realm, history and the future. Buildings should be good neighbours and good hosts'. By emphasising the importance of durability, we can open for architectural continuity. This is again an understanding of architecture that addresses the importance of belonging.

\section{REFERENCES}

Arendt, Hannah, The Human Condition, Chicago: University of Chicago Press 1958

Merleau-Ponty, Maurice, in The Phenomenology of Perception, London and New York: Routledge Classic 1962

Rosbottom, Daniel, see: : https://www.tudelft.nl/en/architecture-and-the-built-environment/about-the-faculty/professors/prof-dj-rosbottom/. Date: $1^{\text {st }}$ of July 2019 

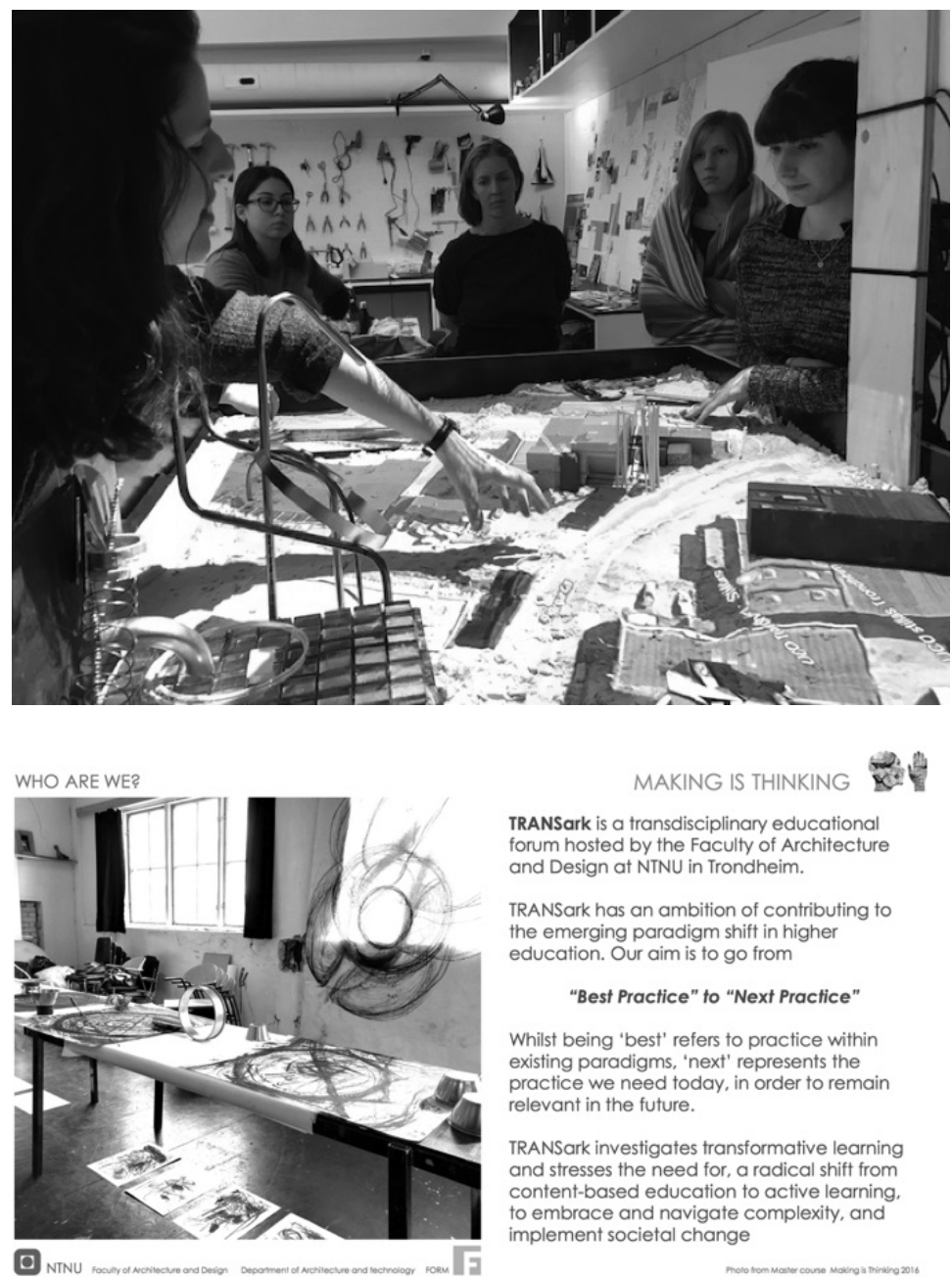

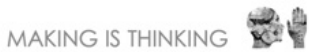

TRANSark is a transdisciplinary educational forum hosted by the Faculty of Architecture and Design at NTNU in Trondheim.

TRANSark has an ambition of contributing to the emerging paradigm shift in higher education. Our aim is to go from

\section{"Best Practice" to "Next Practice"}

Whilst being 'best' refers to practice within existing paradigms, 'next' represents the practice we need today, in order to remain relevant in the future.

TRANSark investigates transformative learning and stresses the need for, a radical shift from content-based education to active learning. to embrace and navigate complexity, and implement societal change 